\title{
Increased expression of a novel splice variant of the complement component $4(C 4 A)$ gene in mastitis-infected dairy cattle
}

\author{
Y. Yang ${ }^{1,2,3}$, J.M. Huang ${ }^{1}$, Z.H. Ju1, Q.L. Li ${ }^{1}$, L. Zhou ${ }^{1}$, R.L. Li ${ }^{1}$, J.B. Li ${ }^{1}$, \\ F.X. Shi ${ }^{2}$, J.F. Zhong ${ }^{1}$ and C.F. Wang ${ }^{1}$ \\ ${ }^{1}$ Dairy Cattle Science Research Center, \\ Shandong Academy of Agricultural Sciences, Jinan, P.R. China \\ ${ }^{2}$ College of Animal Science and Technology, \\ Nanjing Agricultural University, Nanjing, P.R. China \\ ${ }^{3}$ Patent Examination and Cooperation Center of Jiangsu, \\ State Intellectual Property Office, Suzhou, P.R. China \\ Corresponding authors: C. Wang / F. Shi \\ E-mail: wcf1967@yahoo.com.cn / fxshi@njau.edu.cn
}

Genet. Mol. Res. 11 (3): 2909-2916 (2012)

Received September 21, 2011

Accepted February 1, 2012

Published May 18, 2012

DOI http://dx.doi.org/10.4238/2012.May.18.12

\begin{abstract}
The complement system helps in the direct lysis of invading pathogens and modulates phagocytic, humoral and cellular immune responses. Complement 4 is a critical component in complement activity and protection against many bacterial pathogens because it is essential to classical and lectin activation pathways. We used reverse transcription and PCR to investigate alternative splicing and expression of the complement component $4(C 4 A)$ gene in Chinese Holstein cattle. The PCR products were cloned and sequenced. A novel splice variant involving intron 10 was identified, which we named C4A-AS. To examine how C4A gene activity is affected by bovine mastitis, six Chinese Holstein cattle were divided into healthy (nonmastitic) and Staphylococcus aureus-induced mastitic groups. Realtime quantitative PCR (qRT-PCR) revealed that the C4A-complete and C4A-AS transcripts are expressed at significantly different levels in healthy cows, while there were no significant differences in the mastitic
\end{abstract}


group $(\mathrm{P}=0.257)$. Expression of $\mathrm{C} 4 \mathrm{~A}-\mathrm{AS}$ increased significantly when mastitis developed. We also examined the expression of C4A-complete and C4A-AS in several tissues (liver, heart, spleen, lung, kidney, tongue, and muscle). The two transcripts were expressed in all of these tissues but there were no significant differences in expression between healthy and mastitic cows. We therefore conclude that the $\mathrm{C} 4 \mathrm{~A}$-complete transcript is the main transcript under normal physiological conditions, while C4A-AS is augmented when mastitis develops.

Key words: $C 4 A$ gene; Alternative splicing; Transcription pattern; Dairy cattle; Mastitis

\section{INTRODUCTION}

$\mathrm{C} 4$ is a component in the classical and lectin complement pathways, and it plays an important role in host defense. In humans, the $C 4$ gene exists in two copies $C 4 A$ and $C 4 B$ (Dodds and Law, 1990), whereas only the $C 4 A$ gene is reported in bovine. The bovine complement component $4(C 4 A)$ gene is closely linked to the major histocompatibility complex class II region on chromosome 23 (Andersson et al., 1988), which shows significant association with susceptibility to intramammary infections with major pathogens (Rupp and Boichard, 2003). Bovine mastitis is an inflammation of the mammary gland, and related economic losses are the costs of treatment, culling, death and decreased milk production (Bradley, 2002). In cows, the deposition of C4 on Streptococcus agalactiae was increased in the milk of infected glands compared to normal milk (Rainard and Poutrel, 1995). Mastitis could up-regulate the mRNA abundance of the C4A gene in Escherichia coli-infected udders (Günther et al., 2009). This implies a possible relationship between the $C 4 A$ gene and mastitis resistance in dairy cattle.

In humans, $\mathrm{C} 4$ has been examined for association with various diseases, such as systemic lupus erythematosus (Petri et al., 1993), schizophrenia (Morera et al., 2007), 21-hydroxylase deficiency (Guerra-Junior et al., 2008), and diabetes (Vergani et al., 1983). C4 is very complex at both the genomic and protein levels. Different individuals can differ either in number or size of the $C 4$ gene (Yu et al., 1986). The $C 4$ gene demonstrates a high rate of polymorphism (Belt et al., 1985), and C4 protein was also found to be highly polymorphic by electrophoretic (Awdeh and Alper, 1980) and serological typing (Giles, 1984).

Alternative splicing in eukaryotes is a regulatory mechanism for generating potentially many transcript isoforms from a single gene, and it is highly relevant to disease and therapy (Garcia-Blanco et al., 2004; Kim et al., 2007; Ju et al., 2011). A large fraction of the proteincoding genes of multicellular organisms are alternatively spliced (Ast, 2004). Of the 21,755 bovine genes, 4567 (21\%) are alternatively spliced (Chacko and Ranganathan, 2009). The types of AS include exon skipping, alternative 5'-and 3'-splice sites, alternative promoter usage, mutually exclusive exons, intron retention, and alternative polyadenylation (Keren et al., 2010). Thus, AS may be one of the mechanisms by which the diverse physiologic functions of the $C 4 A$ gene are regulated as well. Taken together, we investigated the potential AS patterns of the $C 4 A$ gene in Chinese Holsteins. In addition, the transcripts of the $C 4 A$ gene in different tissues of healthy and mastitic cattle were analyzed to examine their effect on mastitis. 


\section{MATERIAL AND METHODS}

\section{Tissues sample collection}

The milk, tissue of mammary gland in four areas, heart, liver, spleen, lung, kidney, muscle, and tongue were sampled aseptically from 10 culled Chinese Holstein cattle with clinical mastitis and 6 healthy control cows in the slaughterhouse. The milk was stored in an ice box, and tissue samples were obtained immediately after slaughter, snap-frozen in liquid nitrogen until RNA isolation and transported to the laboratory.

\section{Diagnostic tests for identification of Staphylococcus aureus in milk}

The milk isolates of bovine mastitis mammary areas were tested for hemolysis after overnight incubation at $37^{\circ} \mathrm{C}$ on sheep blood agar. Hemolysis was recorded as $\alpha$-hemolysis, $\beta$-hemolysis, double hemolysis $(\alpha+\beta)$, and negative (no hemolysis). DNase activity was tested on DNase test agar following manufacturer recommendations (Tianhe Microorganism, Hangzhou, China). Only strong DNase activities (clear zone around growth similar to that of the S. aureus control strain ATCC 29213) were recorded as positive. Weak DNase activities with clear zones noticeably smaller than that of the positive control were recorded as negative.

Based on the result of diagnostic tests for identification of $S$. aureus in milk, a total of six Chinese Holstein cattle were selected and divided into two groups: normal $(\mathrm{N}=6)$ and $S$. aureus-induced mastitis $(\mathrm{N}=6)$. Total RNA of tissues was extracted with the E.Z.N.A ${ }^{\circledR}$. Total RNA kit II (Omega Bio-tech).

\section{Primer design}

Based on mRNA sequence of bovine $C 4 A$ and $\beta$-actin gene (GenBank accession Nos. NM_001166485.1 and NM_173979.3), the primers (Table 1) were designed with the Primer Premier 5.0 software and synthesized by Sangon Biological Engineering Technology (Shanghai, China).

\section{Preparation and amplification of cDNA}

The isolated RNA was transcribed into cDNA with PrimeScript ${ }^{\mathbb{R}}$ RT Master Mix (TaKaRa, Dalian, China) according to the manufacturer instruction. PCR was performed in a volume of $50 \mu \mathrm{L}$ consisting of $1.0 \mu \mathrm{L}$ cDNA, $1.0 \mu \mathrm{L} 10 \mu \mathrm{M}$ of each primer (C4A1 to C4A4), $5.0 \mu \mathrm{L} 10 \mathrm{X}$ PCR buffer, $1.8 \mu \mathrm{L} 50 \mathrm{mM} \mathrm{Mg}{ }^{2+}, 1.0 \mu \mathrm{L} 10 \mu \mathrm{M}$ dNTP, $0.5 \mu \mathrm{L} 5 \mathrm{U} / \mu \mathrm{L}$ Taq DNA polymerase, and $\mathrm{ddH}_{2} \mathrm{O}$ added up to $50 \mu \mathrm{L}$. An initial denaturation for $5 \mathrm{~min}$ at $94^{\circ} \mathrm{C}$, was followed by 35 cycles of denaturation at $94^{\circ} \mathrm{C}$ for $1 \mathrm{~min}$, annealing at Ta for $1 \mathrm{~min}$, and extension at $72^{\circ} \mathrm{C}$ for $90 \mathrm{~s}$, and a final elongation at $72^{\circ} \mathrm{C}$ for $7 \mathrm{~min}$ (Table 1). The amplification was confirmed by electrophoresis on a $1 \%$ agarose gel with ethidium bromide.

\section{Cloning and sequencing}

The PCR product was purified with the E.Z.N.A. ${ }^{\mathrm{TM}}$ Gel Extraction kit (Omega Bio-tech) 
and ligated to $p E A S Y$-T3 vector (TransGen, Beijing, China), and their mixture was subsequently transformed into DH $5 \alpha$ strain of E. coli. The positive clones were selected randomly and sequenced using an ABIPRISM3730 DNA Sequencer (BGI Biotech Co., Ltd., Qingdao, China).

\section{Real-time quantitative PCR (qRT-PCR)}

PCR was performed using the SYBR ${ }^{\circledR}$ Premix Ex Taq ${ }^{\mathrm{TM}}$ II (TaKaRa) and the Applied Biosystems 7300 Real-Time PCR System in reaction volumes of $20 \mu \mathrm{L}$. The reaction system contained 10.0 $\mu \mathrm{L} \mathrm{SYBR}^{\circledR}$ Premix Ex Taq ${ }^{\mathrm{TM}}$ II, $0.8 \mu \mathrm{L} 10 \mu \mathrm{M}$ forward and reverse primers, 0.4

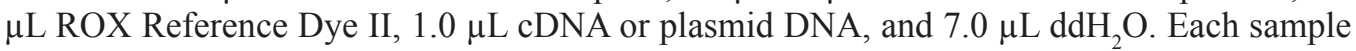
was amplified in triplicate.

The thermal cycling parameters were as follows: a pre-run at $95^{\circ} \mathrm{C}$ for $30 \mathrm{~s}, 40$ cycles with a $5 \mathrm{~s}$ denaturation step at $95^{\circ} \mathrm{C}$ followed by a $60^{\circ} \mathrm{C}$ for $31 \mathrm{~s}$. In addition, bovine $\beta$-actin was used as an internal control. A no-template control (negative control) was included in each assay.

\section{Data mining and statistical analysis}

Alternative splicing detection and sequence analysis were conducted using the BLAST search online resource (http://blast.ncbi.nlm.nih.gov) and the DNAMAN software package (version 6.0, Lynnon Biosoft, Quebec, Canada). The relative quantification of $C 4 A$ gene expression was calculated using the standard curve-based method for real time PCR (Larionov et al., 2005). The analyses were performed using the SPSS 17.0 statistics software. The data were subjected to Student independent-sample $t$-test to determine differences between the means of different groups. The values of the expression level were presented as the mean $\pm \mathrm{SEM}$. Significance was concluded at $\mathrm{P}<0.05$.

\section{RESULTS}

\section{Identification of $C 4 A$ gene transcript variants}

To investigate the possible splicing variants of the bovine $C 4 A$ gene, RT-PCR was performed in the liver and mammary gland tissues. A total 67 clones were selected to sequence (RT-PCR with primer C4A1; other fragments had no detectable AS in the present study; data not shown) and one splice variant was obtained in the liver and mammary gland. The sequence alignment results showed that the splice variant retained intron 10 (Figure 1). Although the fragment length of C4A-AS was longer than the complete sequence transcript, the C4A-AS transcript encoded 492 amino acids, only a part of the $\beta$-chain of bovine $\mathrm{C} 4$. In the current study, the detected frequency of C4A-AS was $4.5 \%$. The sequence of $\mathrm{C} 4 \mathrm{~A}-\mathrm{AS}$ was submitted to the National Center of Biotechnology Information (GenBank accession No. HQ722913).

\section{Quantification of C4A-complete and C4A-AS}

Selective amplification of C4A-complete and C4A-AS was achieved by qRT-PCR using specific primers (Table 1). The relative expression quantities of healthy and $S$. aureus- 
induced mastitic groups are shown in Figure 2A. Data showed that the expression of the two transcripts was significantly different $(\mathrm{P}<0.001)$ in non-mastitic cows, while there was none in the mastitic group $(\mathrm{P}=0.257)$. It is worth mentioning that $\mathrm{C} 4 \mathrm{~A}-\mathrm{AS}$ increased conspicuously when mastitis occurred $(\mathrm{P}=0.030)$. To evaluate whether $\mathrm{C} 4 \mathrm{~A}$-complete and $\mathrm{C} 4 \mathrm{~A}-\mathrm{AS}$ were expressed in other tissues, RT-PCR was performed in tissues of healthy and S. aureus-induced mastitic Chinese Holsteins (Figure 2B). The results confirmed that C4A-AS expression was lower compared to $\mathrm{C} 4 \mathrm{~A}$-complete in the healthy cows but insignificant $(\mathrm{P}>0.05)$. In addition, to make certain that the AS was authentic, RT-PCR products were sequenced.

\begin{tabular}{|c|c|c|c|c|}
\hline Primer & Primer sequence $\left(5^{\prime}-3^{\prime}\right)$ & Fragment size (bp) & $\mathrm{Ta}\left({ }^{\circ} \mathrm{C}\right)$ & Function \\
\hline C4A1 & $\begin{array}{l}\text { S:CATCTTGCTTCTTCGCCTTGT } \\
\text { A:GACGATACGCCTTGGAACTGT }\end{array}$ & 1713 & 59.8 & $\begin{array}{c}\text { RT-PCR } \\
65 \rightarrow 1777\end{array}$ \\
\hline $\mathrm{C} 4 \mathrm{~A} 2$ & $\begin{array}{l}\text { S:CCATTGAGTGGCAGAATCCGC } \\
\text { A:CATCATCCCGTTGCTGCGACA }\end{array}$ & 1923 & 65.5 & $\begin{array}{c}\text { RT-PCR } \\
1451 \rightarrow 3373\end{array}$ \\
\hline $\mathrm{C} 4 \mathrm{~A} 3$ & $\begin{array}{l}\text { S:CAAGACAGAGCAGTGGAGCAT } \\
\text { A:TGCCCCATAAAACACAGAACA }\end{array}$ & 1627 & 59.6 & $\begin{array}{c}\text { RT-PCR } \\
3117 \rightarrow 4743\end{array}$ \\
\hline $\mathrm{C} 4 \mathrm{~A} 4$ & $\begin{array}{l}\text { S:GTGAGAGGAAACAGCAAAGGA } \\
\text { A:AGAGCCTTAGATGATGCCAAC }\end{array}$ & 1343 & 57.0 & $\begin{array}{c}\text { RT-PCR } \\
4136 \rightarrow 5482\end{array}$ \\
\hline$\beta$-actin & $\begin{array}{l}\text { S:GCACAATGAAGATCAAGATCATC } \\
\text { A:CTAACAGTCCGCCTAGAAGCA }\end{array}$ & 173 & 60.0 & Internal control \\
\hline C4A-complete & $\begin{array}{l}\text { S:TAGCACTGATGACCTCCC } \\
\text { A:AAAACAACTTGGCAGACAC }\end{array}$ & 248 & 60.0 & qRT-PCR \\
\hline C4A-AS & $\begin{array}{l}\text { S:GAAGGGGGAGGATGAGCA } \\
\text { A:CGCTCCCATCTGTGTTCTG }\end{array}$ & 221 & 60.0 & qRT-PCR \\
\hline
\end{tabular}

$\mathrm{Ta}=$ annealing temperature.

\section{C4A-complete}

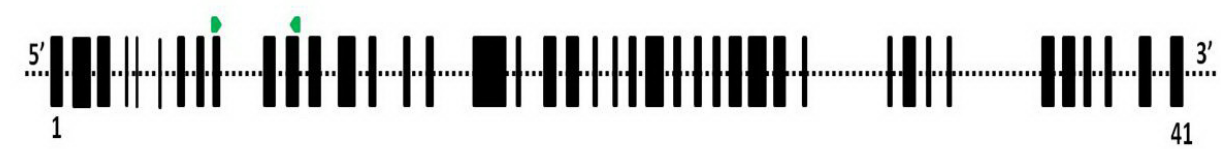

CAA-AS
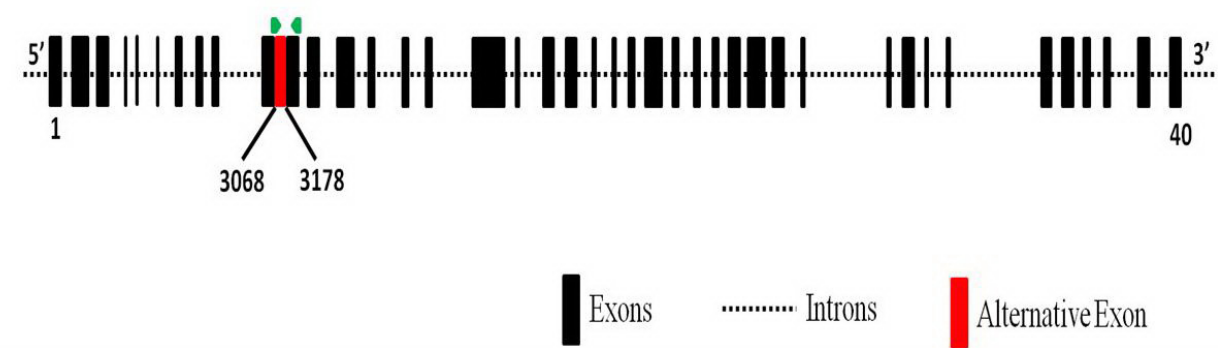

Figure 1. Gene structure and alternative splicing pattern of the $C 4 A$ gene in Chinese Holstein cattle. Green arrows indicate forward and reverse primers for qRT-PCR, and numbers of the first exon and last exon are shown below as corresponding black boxes. C4A-AS is intron 10 retention (111 bp was retained), so the total exon number is 40 . 
(A)

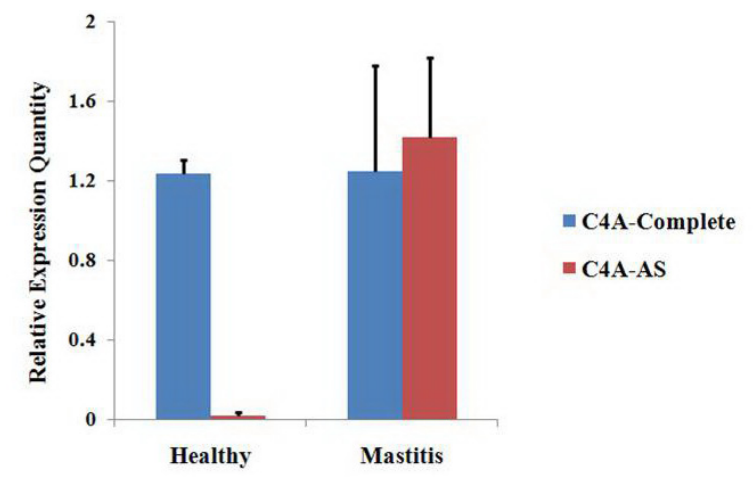

(B)

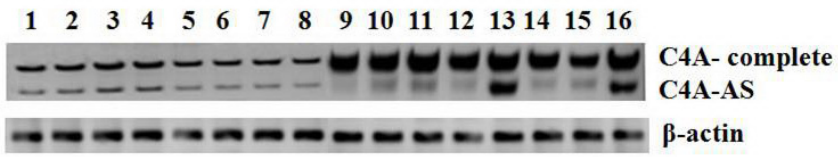

Figure 2. Results of relative C4A-complete and C4A-AS transcript quantification. A. qRT-PCR relative quantification of C4A-complete and C4A-AS in mammary glands of healthy and Staphylococcus aureus-induced mastitic cows. B. Comparison of C4A-complete and C4A-AS transcript levels in several tissues (Lanes 1 and 9 $=$ heart; lanes 2 and $10=$ tongue; lanes 3 and $11=$ lung; lanes 4 and $12=$ spleen; lanes 5 and $13=$ liver; lanes 6 and $14=$ kidney; lanes 7 and $15=$ muscle; lanes 8 and $16=$ mammary glands) in non-mastitic (lanes 1-8) and $S$. aureus-induced mastitic cattle (lanes 9-10).

\section{DISCUSSION}

To date, little is known about $C 4 A$ mRNA expression in cattle, and splice variants of bovine $C 4 A$ have not yet been characterized. In the present study, we reported for the first time the detection of a transcript variant of the bovine $C 4 A$ gene, which shows intron 10 retention. Although this kind of variant may be derived from unspliced or partially spliced pre-mRNAs (Galante et al., 2004), some cases of intron retention with known biologic effect have been proven (Rio, 1991; Le Hir et al., 2002). Therefore, we analyzed the expression quantity of C4A-complete and C4A-AS in healthy and S. aureus-induced mastitic Chinese Holstein cows. Our findings suggest that the C4A-AS may have some actions against $S$. aureus-induced mastitis, owing to the significant increase in diseased individuals.

In humans, people with a short $C 4 B$ gene have higher $C 4$ serum protein levels and higher $\mathrm{C} 4$ hemolytic activity than those with a long $C 4 A$ gene, which contains an endogenous retrovirus HERV-K (C4) in intron 9 (Yang et al., 2003). In H-2 mice, the insertion of the B2 sequence into intron 13 results in low C4 expression in serum (Pattanakitsakul et al., 1992). These findings imply that splicing of the $\beta$-chain could regulate $\mathrm{C} 4$ concentration, consistent with our results. Other components in the complement system also have AS, such as MASP3 , which is generated through alternative splicing of the MASP-1/3 gene (Dahl et al., 2001).

The presence of C4A-AS may be associated with a single nucleotide polymorphism (SNP), which we have identified in exon 10 of Chinese Holstein cattle, C4A gene $(\mathrm{A} \rightarrow \mathrm{G}$, ss262957630). This coincides with the results of Liu et al. (2001), who considered that a coding-region SNP may affect the patterns or efficiency of AS. Our conclusion is also consistent with the results of Hull et al., who believe that there is a highly significant association between splice phenotype and neighboring SNPs (Hull et al., 2007). 
Liver is the major source of $\mathrm{C} 4$. In mice, $\mathrm{C} 4$ is expressed in peritoneal macrophages, liver, mammary gland, lung, spleen and kidney (Cox and Robins, 1988). In humans, C4 is enriched in liver, kidney, thyroid, brain, and breast (Witte et al., 1991). Our RT-PCR results showed that $C 4 A$ is also expressed in heart, liver, spleen, lung, kidney, muscle, tongue, and mammary gland of dairy cattle. Moreover, there were expression differences between the two transcripts of the $C 4 A$ gene in mammary gland tissues from healthy and mastitic groups. Wang et al. (2008) found that the expression of C4 mRNA was first downregulated by lipopolysaccharide challenge and then fluctuated in the zebrafish Danio rerio. And LPS is the main component of E. coli, which is a mastitis-causing bacterium. Herein, we proposed a hypothesis that the C4A-complete transcript was a dominating transcript under normal physiologic conditions, while the expression of C4A-AS was enhanced when the mastitis-causing bacteria such as $S$. aureus invaded or other diseases occurred.

In conclusion, this study showed that one splice variant was identified in Chinese Holstein cattle, which we named C4A-AS. We detected the expression level of two transcripts in several tissues and found that the C4A-AS may have a relationship with mastitis resistance. Since our present study included small samples and lacked randomization, the biologic significance of the C4A-AS transcript requires further study.

\section{ACKNOWLEDGMENTS}

Research supported by the National Anti-TB Transgenic Project (\#2011ZX08007004), National Science and Technology Pillar Program during the 12th Five-Year Plan of China (\#2011BAD19B04), National Natural Science Funds (\#31000543), National Cow Industrial Technology System Program (\#CARS-37) and Key Scientific and Technological Project from Shandong Province (\#2009GG20002033). We express our gratitude to Dr. Reinhold J. Hutz of the Department of Biological Sciences, University of Wisconsin-Milwaukee, USA, for reading the original manuscript and offering valuable suggestions.

\section{REFERENCES}

Andersson L, Lunden A, Sigurdardottir S, Davies CJ, et al. (1988). Linkage relationships in the bovine MHC region. High recombination frequency between class II subregions. Immunogenetics 27: 273-280.

Ast G (2004). How did alternative splicing evolve? Nat. Rev. Genet. 5: 773-782.

Awdeh ZL and Alper CA (1980). Inherited structural polymorphism of the fourth component of human complement. Proc. Natl. Acad. Sci. U. S. A. 77: 3576-3580.

Belt KT, Yu CY, Carroll MC and Porter RR (1985). Polymorphism of human complement component C4. Immunogenetics 21: $173-180$.

Bradley A (2002). Bovine mastitis: an evolving disease. Vet. J. 164: 116-128.

Chacko E and Ranganathan S (2009). Genome-wide analysis of alternative splicing in cow: implications in bovine as a model for human diseases. BMC Genomics 10 (Suppl 3): S11.

Cox BJ and Robins DM (1988). Tissue-specific variation in C4 and Slp gene regulation. Nucleic Acids Res. 16: 6857-6870.

Dahl MR, Thiel S, Matsushita M, Fujita T, et al. (2001). MASP-3 and its association with distinct complexes of the mannan-binding lectin complement activation pathway. Immunity 15: 127-135.

Dodds AW and Law SK (1990). The complement component C4 of mammals. Biochem. J. 265: 495-502.

Galante PA, Sakabe NJ, Kirschbaum-Slager N and de Souza SJ (2004). Detection and evaluation of intron retention events in the human transcriptome. RNA 10: 757-765.

Garcia-Blanco MA, Baraniak AP and Lasda EL (2004). Alternative splicing in disease and therapy. Nat. Biotechnol. 22: 535-546.

Giles CM (1984). A new genetic variant for Chido. Vox Sang. 46: 149-156. 
Guerra-Junior G, Grumach AS, de Lemos-Marini SH, Kirschfink M, et al. (2008). Complement 4 phenotypes and genotypes in Brazilian patients with classical 21-hydroxylase deficiency. Clin. Exp. Immunol. 155: 182-188.

Günther J, Koczan D, Yang W, Nurnberg G, et al. (2009). Assessment of the immune capacity of mammary epithelial cells: comparison with mammary tissue after challenge with Escherichia coli. Vet. Res. 40: 31.

Hull J, Campino S, Rowlands K, Chan MS, et al. (2007). Identification of common genetic variation that modulates alternative splicing. PLoS Genet. 3: e99.

Ju Z, Wang C, Li Q, Hou M, et al. (2011). Alternative splicing and mRNA expression analysis of bovine SLAMF7 gene in healthy and mastitis mammary tissues. Mol. Biol. Rep. DOI: 10.1007/s11033-011-1198-z.

Keren H, Lev-Maor G and Ast G (2010). Alternative splicing and evolution: diversification, exon definition and function. Nat. Rev. Genet. 11: 345-355.

Kim E, Magen A and Ast G (2007). Different levels of alternative splicing among eukaryotes. Nucleic Acids Res. 35: 125-131.

Larionov A, Krause A and Miller W (2005). A standard curve based method for relative real time PCR data processing. BMC Bioinformatics 6: 62.

Le Hir H, Charlet-Berguerand N, de Franciscis V and Thermes C (2002). 5'-End RET splicing: absence of variants in normal tissues and intron retention in pheochromocytomas. Oncology 63: 84-91.

Liu HX, Cartegni L, Zhang MQ and Krainer AR (2001). A mechanism for exon skipping caused by nonsense or missense mutations in BRCA1 and other genes. Nat. Genet. 27: 55-58.

Morera AL, Henry M, Garcia-Hernandez A and Fernandez-Lopez L (2007). Acute phase proteins as biological markers of negative psychopathology in paranoid schizophrenia. Actas Esp. Psiquiatr. 35: 249-252.

Pattanakitsakul S, Zheng JH, Natsuume-Sakai S, Takahashi M, et al. (1992). Aberrant splicing caused by the insertion of the $\mathrm{B} 2$ sequence into an intron of the complement $\mathrm{C} 4$ gene is the basis for low $\mathrm{C} 4$ production in $\mathrm{H}-2 \mathrm{k}$ mice. J. Biol. Chem. 267: 7814-7820.

Petri M, Watson R, Winkelstein JA and McLean RH (1993). Clinical expression of systemic lupus erythematosus in patients with C4A deficiency. Medicine 72: 236-244.

Rainard P and Poutrel B (1995). Deposition of complement components on Streptococcus agalactiae in bovine milk in the absence of inflammation. Infect. Immun. 63: 3422-3427.

Rio DC (1991). Regulation of Drosophila P element transposition. Trends Genet. 7: 282-287.

Rupp R and Boichard D (2003). Genetics of resistance to mastitis in dairy cattle. Vet. Res. 34: 671-688.

Vergani D, Johnston C, Abdullah N and Barnett AH (1983). Low serum C4 concentrations: an inherited predisposition to insulin dependent diabetes? Br. Med. J. 286: 926-928.

Wang Z, Zhang S and Wang G (2008). Response of complement expression to challenge with lipopolysaccharide in embryos/larvae of zebrafish Danio rerio: acquisition of immunocompetent complement. Fish Shellfish Immunol. 25: 264-270.

Witte DP, Welch TR and Beischel LS (1991). Detection and cellular localization of human C4 gene expression in the renal tubular epithelial cells and other extrahepatic epithelial sources. Am. J. Pathol. 139: 717-724.

Yang Y, Chung EK, Zhou B, Blanchong CA, et al. (2003). Diversity in intrinsic strengths of the human complement system: serum $\mathrm{C} 4$ protein concentrations correlate with $\mathrm{C} 4$ gene size and polygenic variations, hemolytic activities, and body mass index. J. Immunol. 171: 2734-2745.

Yu CY, Belt KT, Giles CM, Campbell RD, et al. (1986). Structural basis of the polymorphism of human complement components C4A and C4B: gene size, reactivity and antigenicity. EMBO J. 5: 2873-2881. 